\title{
Molecular mechanisms of glucocorticoids on skeleton and bone regeneration after fracture
}

\author{
Yasmine Hachemi1,*, Anna E Rapp,*, Ann-Kristin Picke', Gilbert Weidinger ${ }^{3}$, Anita Ignatius ${ }^{2, *}$ and \\ Jan Tuckermann ${ }^{1, *}$ \\ IInstitute of Comparative Molecular Endocrinology, Ulm University, Ulm, Germany \\ ${ }^{2}$ Institute of Orthopaedic Research and Biomechanics, Ulm University Medical Centre, Ulm, Germany \\ IInstitute of Biochemistry and Molecular Biology, Ulm University, Ulm, Germany \\ Correspondence should be addressed to J Tuckermann: jan.tuckermann@uni-ulm.de \\ *(Y Hachemi, A E Rapp, A Ignatius and J Tuckermann contributed equally to this work)
}

\begin{abstract}
Glucocorticoid hormones (GCs) have profound effects on bone metabolism. Via their nuclear hormone receptor - the GR - they act locally within bone cells and modulate their proliferation, differentiation, and cell death. Consequently, high glucocorticoid levels - as present during steroid therapy or stress - impair bone growth and integrity, leading to retarded growth and glucocorticoid-induced osteoporosis, respectively. Because of their profound impact on the immune system and bone cell differentiation, GCs also affect bone regeneration and fracture healing. The use of conditional-mutant mouse strains in recent research provided insights into the cell-type-specific actions of the GR. However, despite recent advances in system biology approaches addressing GR genomics in general, little is still known about the molecular mechanisms of GCs and GR in bone cells. Here, we review the most recent findings on the molecular mechanisms of the GR in general and the known cell-type-specific actions of the GR in mesenchymal cells and their derivatives as well as in osteoclasts during bone homeostasis, GC excess, bone regeneration and fracture healing.
\end{abstract}

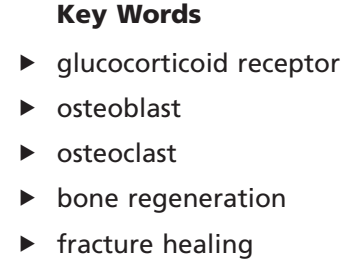

Journal of Molecular Endocrinology (2018) 61, R75-R90

\section{Introduction}

Glucocorticoid hormones (GCs) are major stress hormones released by a hierarchical hormonal axis. The circadian rhythm and psychological and physiological stress trigger the hypothalamus to release corticotropinreleasing factor (CRF), which in turn acts on the pituitary, stimulating its release of adrenocorticotropic hormone (ACTH). ACTH acts on the zona fasciculata of the adrenal cortex for the release of GCs, which belong to the steroid class of hormones. Cortisol as the major GC in humans and corticosterone, the major GC in rodents, act on virtually all cells in the body via the GC receptor (GR) (Baschant et al. 2012) and to a lesser extent through the mineralocorticoid receptor (MR), which displays a restricted expression pattern. GCs by acting on the brain and metabolic organs, including the liver, fat and muscle, contribute substantially to energy metabolism and tissue integrity by affecting cellular proliferation, differentiation, autophagy and apoptosis (Baschant \& Tuckermann 2010). Consequently, energy is mobilised to ensure a fight-orflight response. GCs have a substantial impact on the immune system. They belong to the most potent antiinflammatory agents and are thus in widespread medical use to treat acute and chronic inflammation as well as pain. In addition, they are components of certain cancer

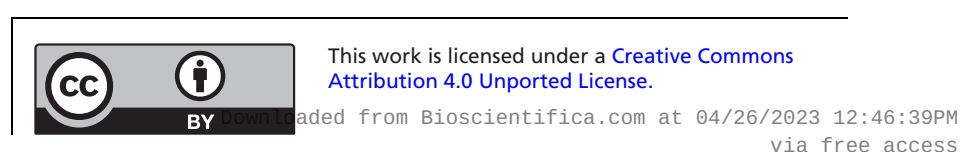


therapies. High GC doses resulting from corticosteroid or from the stress response, induce a number of side effects, including strong effects on the musculoskeletal system. This leads to growth suppression in children and to GC-induced osteoporosis, which elevates the risk for bone fracture (Van Staa et al. 2000). Moreover, because distinct cells of the immune system and skeletal cells are involved in fracture healing, GCs modulate this response and disturbances might contribute to impaired healing responses.

Here, we review the recent mechanistic evidence of how GCs act via the GR and thus affect skeletal cells, and how this translates to alterations in bone mass and modification of fracture healing.

\section{General mechanisms of GC and GR action}

Both endogenous and synthetic GCs exert their effects via nuclear receptors such as the GR (NR3C1) and the closely related mineralocorticoid receptor (MR) (NR3C2); both are ligand-induced transcription factors (De Bosscher \& Haegeman 2009, Joëls \& de Kloet 2017, van Weert \& Meijer 2017). Only in certain MR-expressing tissues, in which GCs are not metabolically inactivated, the MR serves as a high-affinity receptor to mediate responses of low GC concentration. Due to the ubiquitous expression of the GR, the majority of GC effects are mediated by this receptor. In the absence of ligands, the GR is retained in the cytoplasm, because it is sequestered in a multiprotein complex that includes immunophilins and heat shock/chaperone proteins. Upon entering the cell, the bioavailability and activity of the GCs are controlled by the enzymes $11 \beta$-hydroxysteroid dehydrogenase (11ßHSD1) and 11 $\beta$-HSD2, which act in an opposing manner, and regulate the relative levels of cortisone and cortisol (reviewed in Hartmann et al. 2016). Hormone binding induces a conformational change of the GR, allowing its translocation into the nucleus (Hartmann et al. 2016).

The ligand-bound GR can dimerize and bind directly to specific palindromic sequences in the genome (GC responsive elements (GRE) or glucocorticoid receptorbinding sites (GBS)) and in the vicinity to binding sites of tissue-specific transcription factors (reviewed in Hartmann et al. 2016). The bound GR molecules recruit co-regulator proteins and chromatin-remodelling complexes to increase or repress gene transcription (De Bosscher \& Haegeman 2009, Surjit et al. 2011).

In addition to its action as a dimeric molecule, monomeric GR can bind directly to DNA (Schiller et al. 2014, Lim et al. 2015, Weikum et al. 2017) or tether to DNA- bound transcription factors involved in inflammation. Interaction with for instance nuclear factor kappa B (NF-kB), activator protein 1 (AP-1) and interferon response factor 3 (IRF3), leads to repression of gene expression (De Bosscher \& Haegeman 2009). Previously, it was considered that monomer-dependent tethering of the GR was the main mechanism of the anti-inflammatory actions of GCs (De Bosscher \& Haegeman 2009). This view was challenged by numerous studies using mice with a point mutation in one of the dimerization interfaces of the GR, GR dim mice, demonstrating that GR dimer-dependent gene expression is indispensable for most anti-inflammatory effects (reviewed in Hübner et al. 2015). This is remarkable, because a point mutation in one of the GR dimerization domains does not entirely abrogate GR dimerization under in vitro conditions (Presman et al. 2014). However, genome-wide in vivo studies demonstrated an absence of binding to classical GR-binding sites (Lim et al. 2015). In addition to tethering, the GR can bind to a GRE half-site located within AP-1 response-element motifs. This direct interaction is important for transcriptional repression, and monomeric GR appears to be favoured at these sites (Weikum et al. 2017).

In addition to transcriptional activity, GCs can exert nongenomic effects. These effects are rapid and are only observed following high-dose GC treatment (Stahn \& Buttgereit 2008). Under such conditions, GCs are considered to interact with plasma and mitochondrial membranes and affect their physicochemical properties, thereby altering their function. GCs can also bind to the cytosolic GR (cGR) and a membrane-bound GR (mGR) (Stahn \& Buttgereit 2008), and then modulate mitogenactivated protein (MAP) kinase activity, leading to the regulation of other non-GR signalling pathways (reviewed in Hartmann et al. 2016). The impact of the nongenomic GR actions in bone cells and towards the contribution to GC effects on bone remains elusive.

Taken together, multiple molecular mechanisms are exerted by the GR to mediate GC effects. These include genomic effects by the induction and repression of gene expression in a cell-type-specific manner and nongenomic rapid effects in particular at high GC doses.

\section{GC action in bone - lessons from mouse models}

In a hallmark study, Weinstein and colleagues (Weinstein et al. 1998) described a model of prednisolone slow release pellets leading to bone mineral density changes in Swiss Webster mice. Since then, the mouse became a popular

This work is licensed under a Creative Commons Attribution 4.0 Unported License. 
model in preclinical GC-induced osteoporosis (GIO) research. The major advantage of mice in osteoporosis research, in contrast to rats or rabbits, is the possibility of testing the importance of genes in loss of functions, gain of functions and knock-in models. In common with humans, mice depict the strong decline of bone formation and some mouse strains also exhibit the early onset of resorption (reviewed in (Wood et al. 2017)). Most of the molecular mechanisms of GC action on the skeleton that were proven in vivo stems from these models. However, there are also certain limitations using mice. First of all, mice do not have osteons (Haversian system) in cortical bone, and thus, effects on cortical bone might differ from those in humans. Second, there is a strong variety in GC effects on bone concerning different mouse strains. Swiss Webster mice described by Weinstein and colleagues (Weinstein et al. 1998) are not suitable for studies of transgenic animals, since these are backcrossed into inbred strains, most often C57BL/6, 129SveV, Balb/c or $\mathrm{FVB} / \mathrm{N}$. C57BL/6 does not show strong alterations to GCs concerning their bone mass at younger age due to a relatively low bone mass. Unfortunately, most transgenic mouse strains are crossed to this background. Balb/c and $\mathrm{FVB} / \mathrm{N}$ mice seem to be a better choice, since they show also alterations in bone mass at younger age due to GC (e.g. prednisolone treatment). For example, the studies with mice with conditional GR deletion or impaired GR dimerization were performed in $\mathrm{FVB} / \mathrm{N}$ strains (Rauch et al. 2010). Arrival of CRISPR/Cas9-mediated gene editing, offers now the possibility to expand the functional tests of gene-encoding molecules in mice, and also in other species, which cover other aspects of human GIO. Finally, the application of GCs towards the animals to cause GIO varies greatly concerning ligands (dexamethasone, prednisolone and others), the route of application (intraperitoneal injections, slow-release pellets and oral gavage) as well as dosage and duration (from a couple of days until several months). This hampers the comparison of the different studies (reviewed in Wood et al. 2017). Here, standardization is of utmost need. Despite these shortcomings, much was learned from mouse models and the conclusions are detailed below.

\section{GC-induced osteoporosis}

Long-term corticosteroid therapy leads to complex effects on bone. A rapid initial bone loss is followed by a slow constant long-lasting decline in bone mass (Canalis et al. 2007). In particular, this increases the fracture risk of the femoral neck and vertebrae (Weinstein 2012).
The systemic actions of GCs, including the disturbance of $\mathrm{Ca}^{2+}$ absorption and reabsorption, sex-steroid levels and the growth hormone axis and increased muscle atrophy, may contribute to the adverse effects of GCs on bone. However, direct actions of GCs on bone cells seem to be more decisive in GIO development. These are the mesenchymal cell-derived bone-forming osteoblasts and their matrix-embedded descendants, the osteocytes, as well as the haematopoietic lineage-descended boneresorbing osteoclasts.

Osteoblasts, osteocytes and osteoclasts work in concert in so-called bone-remodelling units to maintain bone mass. Bone resorption is initiated by the fusion of monocyte precursor cells to form osteoclasts in response to receptor activator of NF-kB ligand (RANKL) and other soluble and membrane-bound factors. In addition to osteoblasts, osteocytes were recently discovered to be a major source of osteoclast-inducing factors, including RANKL (Nakashima et al. 2011, Xiong et al. 2011) and others (Liu et al. 2017). The multinucleated osteoclasts generate a sealing zone at their basolateral side and create an acidic compartment that allows the degradation of mineralised matrix. Under normal physiological conditions, this process is terminated by a still poorly understood coupling mechanism that terminates osteoclast activity and subsequently activates osteoblast activity to form new bone followed by mineralisation (Henriksen et al. 2014) (Fig. 1).

The disturbance of these processes leads to bone loss because of enhanced bone resorption and/or diminished bone formation. Cell-type-specific genetic modulation of bone cells in mice confirmed the strong cell-autonomous impact of GCs on bone mass.

\section{GC excess on osteoclasts}

Osteoclast activity is greatly increased at the onset of GC excess, but declines with prolonged GC excess. This dual activity results from complex, in part opposing, mechanisms of GCs on osteoclast function and maturation.

In particular, in cell systems, an induction of RANKL by simultaneously reducing the osteoclast differentiation inhibitor osteoprotegrin (OPG) was observed (Hofbauer et al. 1999, Rauner et al. 2011). However, in other studies, GCs failed to induce RANKL (Rauch et al. 2010, Piemontese et al. 2016). Intriguingly, RANKL inhibition by denosumab in humanized mice ameliorated to a certain extent the GC-mediated bone loss (Hofbauer et al. 2009). Genetic inactivation of RANKL in osteocytes reduced the

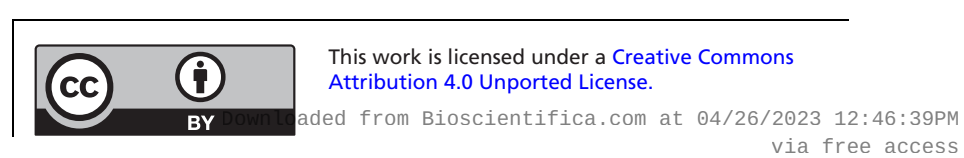




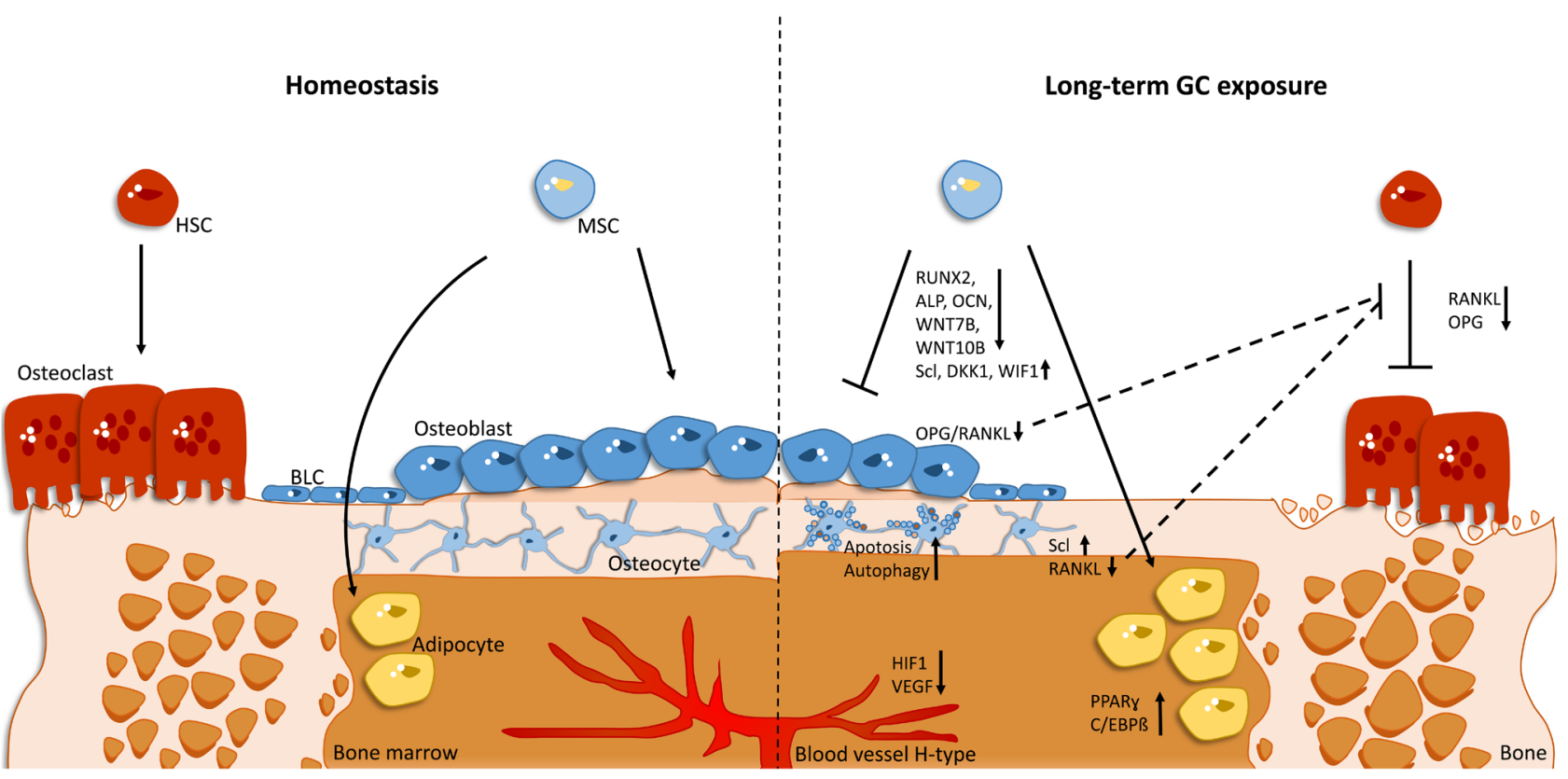

Figure 1

Effect of long-term glucocorticoid (GC) treatment on bone homeostasis. Homeostasis: In homeostasis (A), bone remodelling is balanced by the activity of bone-resorbing osteoclasts and bone-forming osteoblasts. The differentiation of osteoclasts from haematopoietic stem cells (HSC) is induced by binding of receptor activator of NF-KB ligand (RANKL) and is inhibited by osteoprotegerin (OPG). Osteoblasts derive from mesenchymal stem cells (MSC), which can also differentiate into fat-storing adipocytes. During bone formation, osteoblasts further differentiate into osteocytes or become bone-lining cells (BLC). H-type blood vessels provide nutrients and oxygen for bone cells. Long-term GC exposure: Long-term GC treatment reduces bone mass by a decreased osteogenic and concurrent increased adipogenic differentiation, leading to elevated bone marrow adiposity. This is caused by both a decreased expression of RUNX2, alkaline phosphatase (ALP), osteocalcin (OCN), and Wnt ligands (7b, 10b) and a simultaneous increase in expression of Wnt signalling inhibitors, including sclerostin (SCL), dickkopf-1 (DKK1), and Wnt-inhibitory factor (WIF1), as well as the adipogenic markers peroxisome proliferator-activated receptor $\gamma$ (PPAR $\gamma$ ) and CCAAT/enhancer-binding protein beta (C/EBP). Furthermore, osteoblasts and osteocytes synthesize less RANKL, and thus shift the RANKL/OPG balance towards less osteoclast differentiation and activity. In addition, osteoblasts and osteocytes undergo an increased amount of cell death (apoptosis) and autophagy. The supply of nutrients and oxygen by the specific $\mathrm{H}$-type vascular subtype for bone cells is diminished by GC exposure via downregulation of hypoxia-inducible factor 1-alpha (HIF1) and vascular endothelial growth factor (VEGF). In summary, bone remodelling slows down on long-term GC exposure, leading to reduced bone mass.

cortical bone loss induced by GC treatment, but not in the trabecular bone. In conclusion, RANKL expression is at least in part involved in GC-mediated bone loss.

Intriguingly, osteoclast development from monocytic progenitors is suppressed by GCs (Jia et al. 2006, Kim et al. 2006), explaining the long-term decline of bone resorption during GC excess. This appears to be in part due to the impairment of the cytoskeletal reorganization influencing Rac activity and calpain 6 expression (Hong et al. 2011). However, increased osteoclast longevity was suggested to explain the initial enhanced resorption (Jia et al. 2006). Recently, it was found that the initial inhibitory effects of GCs on osteoclastogenesis are compensated by a direct increase of resorption activity of the remaining osteoclasts (Conaway et al. 2016, Shi et al. 2015) in a GR dimerizationdependent manner in mice (Conaway et al. 2016), presumably by increasing reactive oxygen species (ROS) levels (Shi et al. 2015). Taken together, GCs act directly on osteoclasts, increasing their resorptive activity, and also lead to a decline in the long term of bone turnover (Fig. 1).

\section{GC excess on osteoblasts and osteocytes}

Inhibition of bone formation is the major feature of GIO (Hartmann et al. 2016). This mainly results from impaired osteoblast function. Because osteocytes derive from the osteoblast lineage, GC impact on osteoblast abundance and function also contributes to the effect of GCs on osteocyte fate. Moreover, direct effects of GCs on osteocytes frequently lead to osteocyte death (O'Brien et al. 2004), which can be seen histologically as bone lacunas devoid of osteocytes, and thus, might have a direct impact on bone quality. We subsequently discuss here the impact of GCs on the development of the osteoblast lineage, on the proliferation, expansion and differentiation of osteoblasts and finally, on autophagy and apoptosis of osteoblasts and osteocytes. 


\section{GC effects on progenitor cells and/or skeletal stem cells}

The progenitor cells of osteoblasts are commonly considered to be mesenchymal stem cells (MSCs). These cells were originally defined as stromal bone marrow cells with multi- or at least tri-lineage differentiation potential into adipocytes, osteoblasts or chondrocytes. Finally, MSCs should be capable to give rise to new bone when transplanted ectopically into rodents (Caplan 1991). Numerous tissue-culture experiments demonstrated a decisive role for GCs in promoting MSC differentiation.

Some experimental conditions suggested that GCs contribute to adipocyte differentiation and that this would be at the expense of osteogenic differentiation, providing an attractive model to explain two side effects of GC excess, namely fat redistribution and GIO (Salem \& Thiemermann 2010). Certain studies provide mechanistic clues that GCs are strong inducers of fat-cellspecific transcription factors, including C/EBPs, which subsequently induce peroxisome proliferator-activated receptor $\gamma(\operatorname{PPAR} \gamma)$, the lineage-determining adipocytic transcription factor (Kawai et al. 2012). Accordingly, patients with GIO display high bone marrow adiposity (Rosen \& Bouxsein 2006).

However, there are some conceptual problems with the cultures of so-called MSCs. For example, in GC-treated animals, bone marrow-derived MSCs display enhanced proliferation and subsequent mineralisation (Sui et al. 2016). A further major caveat is that the source for in vitro studies varied from bone marrow stromal cells to adiposetissue stromal cells and ectodermal-derived calvarial pre-osteoblasts. Surprisingly, all of these cultures can be directed into distinct differentiation direction, given that the respective culture medium cocktail is provided. These cultures frequently contain cells of mixed character, and it remained unclear whether they originated from homogenous progenitors or whether these cultures consist of a mixture of distinct, specifically committed cells that expand only under the respective conditions. Furthermore, we observed that impaired GR dimerization in cells of GRdim mice (described earlier) completely abrogates the induction of adipocytes from progenitor cells (Asada et al. 2011), but still suffices to mediate inhibition of osteoblastogenesis by GCs (Rauch et al. 2010). This points to the possibility that the molecular mechanisms of adipogenesis induction and osteogenesis repression by GCs are different.

Finally, the localisation of these MSCs in vivo was for a long time unclear. Recently, by lineage tracing, several mesenchymal and skeletal stem cells have been identified in vivo with multiple differentiation potentials, which are also activated during tissue repair (Ono et al. 2014, Chan et al. 2015, Worthley et al. 2015). These cells, defined by different transgenic mouse Cre lines, were able to give rise to multiple mesenchymal cell types, including osteoblasts, and are located close to the vasculature as perivascular cells (Kassem \& Bianco 2015). Other osteoblast precursors are located at the periosteum (Grcevic et al. 2012). These periosteal progenitor cells have been identified by lineage tracing with Prx1-CreERT2, Osx-CreERT2, aSMACreERT2 and Gremlin1CreERT2 mice (Grcevic et al. 2012). These bone-lining cells can give rise to a substantial number of bone-forming osteoblasts when mature osteoblasts were genetically eliminated (Matic et al. 2016). GC treatment significantly reduced the bone-lining cells. However, whether the effects on bone-lining cells are pivotal in reducing bone formation currently remains unclear. To this end, also the bone marrow residing stem cells and their descendants need to be mapped under GIO conditions. In conclusion, whether GCs shift the balance of multipotent MSCs or only affect the differentiation of pre-committed osteoblast precursors, including bonelining cells, currently remains to be determined.

\section{Osteoblast proliferation}

Inhibition of osteoblast proliferation by GCs depends in part on direct regulation of cell cycle activators, for example, CDK2, 4, 6, CyclinD, c-Myc and E2F-1, and inhibitors, including p21 and p27, by the GR (reviewed in Komori 2016). Interference in MAP kinase pathways by the induction of dual specific phosphatase (DUSP)1, a direct GR target, strongly ameliorates osteoblast proliferation (Horsch et al. 2007). However, DUSP-1 absence in knockout mice did not prevent GC-mediated bone loss, indicating a minor role for MAPK-pathway inhibition (Conradie et al. 2011).

\section{Osteoblast differentiation}

One major mechanism of impaired bone formation is the inhibition of osteoblast differentiation. GR monomer activity as a molecular mechanism appears to be sufficient to suppress osteoblast differentiation in vitro and bone formation in vivo, because GR dim mice display a normal response to GCs (Rauch et al. 2010). Pharmacological doses reduce the expression of key transcription factors for osteoblastogenesis, including runt-related transcription 
factor 2 (RUNX2) and osterix (OSX), the marker enzyme alkaline phosphatase, the late-stage marker osteocalcin and bone mineralisation (reviewed in Frenkel et al. 2015). Furthermore, Wnt ligands, which are decisive for osteoblast proliferation and differentiation, are reduced, in particular WNT7B and WNT10 (Mak et al. 2009). In contrast, Wnt inhibitors, including dickkopf-1 (DKK1), Wnt inhibiting factor 1 (WIF1) and sclerostin, are induced by GCs (reviewed in Hartmann et al. 2016).

Bone morphogenetic protein 2-dependent signalling strongly counteracts the negative effects of GCs on osteoblasts (Frenkel et al. 2015). GCs further act negatively on osteoblast differentiation by inducing Notch signalling (reviewed in Frenkel et al. 2015). Finally, inhibition of AP-1-dependent interleukin (IL)-11 expression by the monomeric GR appears to affect osteoblast differentiation substantially and explains the GR monomer-dependent bone loss (Rauch et al. 2010).

Recent studies suggested that in addition to GC-regulated proteins, microRNAs could also serve as effectors of GC actions. Although several microRNAs are described as important for osteoblast differentiation (reviewed in Hartmann et al. 2016), a recent study in mice with an osteoblast-specific deletion of Dicer, abrogating the generation of the majority of miRNAs, demonstrated that nonetheless the bone formation rate could still be diminished by GCs (Liu et al. 2016). Therefore, regulating miRNAs to inhibit bone formation is not essential for GC action on bone loss.

The reduction of osteoblasts and the accompanying decrease in bone formation was also attributed to GC-induced apoptosis. GC treatment increased the apoptosis rate of osteoblasts in mice and humans (Weinstein et al. 1998). This was prevented by bisphosphonates, calcitonin (Plotkin et al. 1999) and parathyroid hormone (PTH) administration (Jilka et al. 1999). Apoptosis in osteoblasts is initiated by the induction of the pro-apoptotic proteins Bim and Bak, in part via the induction of the transcription factor E4bp4 (Espina et al. 2008, Chang et al. 2009, Chen et al. 2014). Simultaneously, a decrease of the anti-apoptotic protein BcXL (reviewed in Komori 2016) occurs. GCs activate the kinase Pyk2 by $\mathrm{Ca}^{2+}$-influx induction, leading to Jun-Nterminal kinase (JNK) activation (Plotkin et al. 2007). By inducing an accumulation of ROS via activation of p66Shc kinase, GCs can further tip the balance towards cell death (Almeida et al. 2011).

To what extent osteoblast apoptosis contributes to bone loss still remains unclear. The fraction of apoptotic osteoblasts is elevated threefold by GC excess, but still does not represent a large percentage of the cells (Weinstein et al. 1998). Additionally, osteoblasts and osteoclasts from mice overexpressing $11 \beta$-HSD2 under the osteocalcin promoter to impair GC signalling in osteoblasts are resistant to elevated apoptosis (O'Brien et al. 2004). However, these mice display reduced bone mass. In contrast, vertebral compression strength is preserved in these mice. Therefore, while apoptosis contributes to GC actions on the skeleton, impaired bone formation appears to be less dependent on this process (O'Brien et al. 2004). In contrast to osteoblasts, osteocyte apoptosis is very high and particularly impacts on bone quality (Jilka et al. 2013).

\section{Effects of GCs on osteocytes}

Osteocytes are embedded in bone matrix, residing in so-called lacuna. They are interconnected with dendritic processes and build with other osteocytes the lacunacanalicular network (Dallas et al. 2013). As a major source of RANKL (Nakashima et al. 2011, Xiong et al. 2011) and because of to their expression of OPG and nitric oxide (NO), they modulate bone resorption. By releasing dentin matrix acidic phosphoprotein 1 (DMP1) and fibroblast growth factor 23 (FGF23), they also regulate phosphate homeostasis (Feng et al. 2006). Osteocytes on the one hand by expressing the Wnt inhibiting factors sclerostin (SOST, Scl), DKK1 and secreted frizzled-related protein (SRFP1) inhibit osteoblasts. On the other hand by increasing osteoblast-promoting $\mathrm{NO}$ and prostaglandin E2 osteocytes control bone formation (Dallas et al. 2013). Sost is upregulated during GC exposure in mice and rats (Sato et al. 2016, Beier et al. 2017), while Sost deficiency in part abrogates GC effects (Sato et al. 2016) by influencing crosstalk to resorption, but strikingly does not protect against GC-mediated inhibition of bone formation or stimulation of apoptosis. By contrast, Scl-neutralising antibodies prevent cancellous bone loss in part and apoptosis (Achiou et al. 2015), thereby restoring bone formation (Yao et al. 2016).

In addition to apoptosis induction, GCs were reported to induce macro-autophagy in osteoblasts, but also prominently in osteocytes. Intriguingly, lower GC dosage induced increasing autophagy in osteocytes rather than apoptosis (Jia et al. 2011), which is presumed to protect them from cell death. Using autophagy reporter mice (LC3-dsREd fusions), enhanced autophagy was detected in vivo upon prednisolone treatment (Yao et al. 2016). However, this was challenged by studies in mice lacking the autophagy key molecule Atg7 in late-stage osteoblasts and osteocytes (Piemontese et al. 2015). These mice

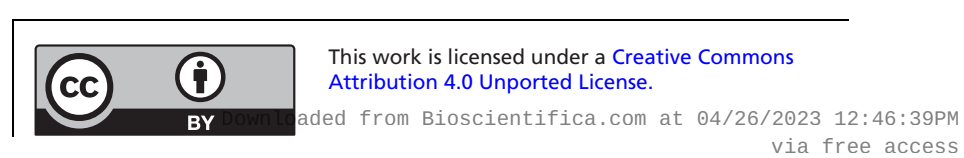


exhibited less cancellous bone, but this was not further affected by prednisolone. Whereas prednisolone failed to increase autophagic flux in the mutant mice, there was no difference in cortical bone in response to prednisolone. The precise role of autophagy still needs to be carefully established, but presumably participates only partially in GC effects on bone.

\section{GC excess on vasculature}

The vasculature has been recently established to have a decisive role in bone integrity and strength (Kusumbe et al. 2014). A specific vascular subtype, the so-called type $\mathrm{H}$ endothelium, is coupled to bone growth, builds a microenvironment for osteoprogenitor cells and is lost during ageing. Increasing hypoxia-inducible factor 1-alpha (HIF1) activity and subsequent vascular endothelial growth factor (VEGF) expression increases bone mass and osteoblast-marker gene expression in aged mice (Kusumbe et al. 2014). GC excess appears to affect HIF1 and VEGF expression, affecting vasculature volume and surface (Weinstein et al. 2010, 2017). GC signalling in osteoblasts in part appears to be decisive, because abrogation of GC signalling in OG2-11 $\beta$-HSD2 transgenic mice prevents the decrease in vasculature volume.

\section{GC excess impairs growth}

A striking clinical problem is the negative effects of GC excess on children's growth by reducing bone growth. Withdrawal of pharmacological GC exposure leads to catch-up growth, an as yet very poorly understood phenomenon. Longitudinal bone growth depends on the proliferation and subsequent differentiation of chondrocytes in the growth plates. Chondrocytes differentiate to hypertrophic chondrocytes and the subsequent vascularisation of hypertrophic cartilage allows the replacement of cartilage with bone in the process of endochondral ossification. Overall, this process is controlled by the growth hormone (GH)-insulinlike growth factor 1 (IGF1) axis; whereas GH triggers IGF1secretion in the liver, both act on the cartilaginous growth plate in growing bones. GC excess is accompanied by a decline in GH and IGF1 titres as well as action (Jux et al. 1998), but this is challenged by studies reporting increased IGF1 receptor and GH receptor expression upon GC exposure (Heinrichs et al. 1994, Smink et al. 2002).

Exogenous GCs inhibit chondrocyte proliferation and increase hypertrophic chondrocyte apoptosis in the growth plate, resulting in impaired bone growth.
Indeed, results from ex vivo cultures of human growthplate cartilage suggest a differential regulation of $\mathrm{Bcl}-2$ family member proteins by GCs, promoting apoptosis in proliferative chondrocytes (Zaman et al. 2014). By contrast, endogenous GCs appear to play a minor role in growth-plate chondrocytes, as indicated by the normal growth-plate phenotype of mice lacking the GR in these cells (Tu et al. 2014, and -reviewed in Hartmann et al. 2016).

\section{GC excess activating the mineralocorticoid receptor (MR)}

The MR has a higher or similar affinity than the GR towards a variety of GCs such as the endogenous GCs cortisol and corticosterone, and still an affinity to the synthetic GR agonists beta-methasone and prednisolone (Lan et al. 1982). Thus, in part excess of endogenous GCs or high pharmacological concentrations of prednisolone also activate MR. Therefore, the GR/MR balance concept was proposed for tissues expressing both receptors, such as the brain (Joëls \& de Kloet 2017). This led to a new concept: at low concentrations of GCs primarily MR is activated, whereas at high concentrations GR is activated and eventual both receptors exert distinct and overlapping function. Even the presence of GR/MR heterodimers is postulated. Tandem ChIP Seq analysis showed binding regions for both receptors, suggesting them in a common complex in the hippocampus (Mifsud \& Reul 2016). MR and GR expression was determined in human foetal bones by Beavan and colleagues (Beavan etal.2001) and indicated immunoreactivity and expression for both receptors in osteoclasts, osteoblasts, and osteocytes. Therefore, for bone the MR/GR balance concept could be valid as well. The functional involvement of MR was addressed by Ikeda and colleagues who blocked MR function with eplerenone (Fumoto et al. 2014). In a model of GIO by application of prednisolone this pharmacological blockade of MR lead to a decreased reduction of trabecular and cortical bone mass. Unfortunately, whether inhibition of MR leads to an attenuated reduction of bone formation rate by prednisolone was not analysed. Interestingly, the lack of MR in late-stage osteoblasts and osteocytes using MRflox;Dmp1Cre mice showed less reduction of trabecular bone in femur by GCs than control mice, whereas the reduction of cortical thickness was completely unaffected (Fumoto et al. 2014). Taken together, MR contributes to GC excess mediated bone loss eventually in part by acting on osteocytes, however, the role of MR in individual bone cell types seems to be less important than the GR. 


\section{Effects of selective GR ligands on bone}

The discrimination of GR monomer function and GR dimerization was also addressed pharmacologically since the 1990s. The aim was to favour transrepression of pro-inflammatory genes by the GR monomer and to avoid the transactivation of metabolic acting genes by GR dimers. The hope was to identify GR ligands with antiinflammatory efficacy similar like classical GR agonists, but with a better side effect profile, including sparing of the bone (Schäcke et al. 2007). Given the findings in mice with impaired GR dimerization and what we know nowadays about the molecular requirements to suppress inflammation, this concept was retrospectively too simplistic, but state of the art in those days (Beato et al. 1995). The first generation were so-called selective GR agonists (SEGRAs) that still exert a steroid backbone and bind to the ligand pocket of the GR (Schäcke et al. 2007). These compounds possessed anti-inflammatory efficacies in certain distinct inflammatory paradigms, such as croton-oil induced inflammation. Of note for croton-oil induced inflammation was one of the few inflammatory diseases, in which also GRdim mice (with intact GR monomer) turned out to be responsive (Reichardt et al. 2001). In contrast $\mathrm{GR}^{\mathrm{dim}}$ mice failed for most other inflammatory diseases tested so far to exert reduction of inflammation by classical GR agonists. Accordingly, compounds for topical treatment of skin inflammation, such as mapracorat (ZK245186), are now tested in clinical trials for atopic skin diseases. However, some of these compounds with steroidal scaffold still exert side effects (reviewed in Strehl et al. 2017). The next generation compounds were so-called selective GR modulators, SEGRMs with non-steroidal scaffolds (reviewed in Sundahl et al. 2015). These modulators are not binding to the ligand-binding pocket. The most prominent example is the shrub-derived compound A (CpdA). Recently, for SEGRAs, the anti-inflammatory efficacy was increased by introducing electrophilic covalent-binding warheads to improve longer residence of the ligands at the GR binding pocket (Chirumamilla et al. 2017). Because of the overall findings that GR dimerization is crucial to confer suppression of inflammatory processes via transactivation of anti-inflammatory acting genes (such as Dusp1, Anxa1, Sphk1 and others), also GR dimer inducing agents were postulated to improve steroid therapy (De Bosscher et al. 2016). Apart from the concept of GR dimer/monomerization selectivity, ligands were developed that induce a differential shift of the helix 12 in the ligand-binding domain. Accordingly, this leads to different co-activator/co-repressor interaction. Indeed such compounds also might exert a decreased side effect profile (Hu et al. 2011).

Comprehensive information on how these selective GR agonists/modulators affect bone is currently lacking. Humphrey and colleagues analysed the effect of several compounds (RU24858, RU40066, RU24782, AL438-F1 and ZK216348) on the OPG/RANKL ratio. They concluded that these compounds suppress the OPG/RANKL ratio less than prednisolone in two human osteoblast cell lines (Humphrey et al. 2006), suggesting that bone resorption by osteoclast is less induced than with full GR agonists. For the GR modulator PF-802, exerting different Helix12 shifts and thus co-regulator recruitments, a lack of suppression of osteocalcin was described (Hu et al. 2011) in vitro.

Some of the selective agents were, however, analysed in more detail on bone metabolism in vivo. For the GR modulator AL-438 selected on the base of differential co-regulator recruitment, a clear lower suppression of bone formation rate was described, thus sparing GC effects on bone (Coghlan et al. 2003).

Another striking compound leading to differential co-regulator recruitment is LGD-5552. LGD-5552 does not impair bone formation rate at lower concentrations but still exert anti-inflammatory effects (Miner et al. 2007).

The GR mimetics containing diazaindole moieties ((R)-18 and (R)-21 were described to have less effect on bone mass than prednisolone. And this was demonstrated even at concentrations showing a stronger reduction of inflammatory disease score than prednisolone in a model of collagen-induced arthritis (Harcken et al. 2014). This was one of the few studies that examined GIO in the context of inflammation with novel GR modulators.

The shrub derived CpdA, a non-steroidal GR modulator showed initial promising results by not inducing RANKL/OPG ratio (Rauner et al. 2011), and not affecting osteoblast differentiation (Rauch et al. 2011). Furthermore, CpdA was suppressing IL11 expression in osteoblasts (Rauch et al. 2011). Since IL-11 is suppressed in mice with impaired GR dimerization and is decisive for inhibition of osteoblast differentiation (Rauch et al. 2010), this leads to the assumption that CpdA might not induce GR-AP-1 interference in stromal cells (De Bosscher et al. 2013). In vivo, CpdA indeed did not affect bone formation and was not increasing resorption in mice (Thiele et al. 2012). Despite these positive findings, the toxicity of CpdA due to rapid degradation into toxic products dampens the promise of this compound. However, these results show that tissue selective GR modulation as exerted by CpdA

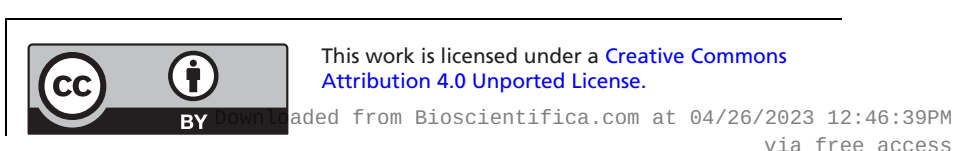


(Rauch et al. 2011, Thiele et al. 2012) or (R)-18 and (R)21 (Harcken et al. 2014), could be a strategy to combat certain inflammatory diseases and spare bone mass.

\section{Endogenous GC action on bone}

Endogenous GCs are necessary for physiological bone metabolism. Targeted overexpression of $11 \beta-\mathrm{HSD} 2$ in osteoblasts and osteocytes in Col2.3-11 $\beta$-HSD2 transgenic mice led to reduced cortical and trabecular bone mass (Sher et al. 2004, 2006, Kalak et al. 2009), but only at selected sites, and delayed cranial-bone development (Zhou et al. 2009). Augmented Wnt signalling by low dose GCs, but shut down by high-dose GCs, could be one mechanism of anabolic effects of GCs at physiological concentrations (Mak et al. 2009). By contrast, studies conducted in aged mice demonstrated increased skeletal fragility by endogenous GCs, leading to impaired bone angiogenesis and decreased vasculature volume (Weinstein et al. 2010).

The effects of endogenous GCs could be exerted by both MR and GR. Due to the higher affinity of MR towards GCs, effects of low GC concentration could be rather mediated by the MR than the GR. However, ablation of the MR in osteoblasts in MRflox;OsxCre mice and in osteocytes in MRflox;Dmp1Cre mice did not alter trabecular bone mass substantially (Fumoto et al. 2014). Nonetheless, blockade of wild type mice with the MR antagonist epleronone lead to an increase of trabecular bone mass, bone formation rate, and reduced osteoclasts. Thus, the MR impacts negatively on basal bone integrity (Fumoto et al. 2014). However, the cell types involved remain to be elusive, e.g. the role of MR in osteoclasts, but also in complete other organs can be anticipated. It also remains unclear whether the MR mediates GC effects at all, since ablation of GC signalling rather decreases bone mass. A negative impact of aldosterone acting via the MR can not be excluded.

In contrast to blockage of $\mathrm{MR}$, but similarly to inhibition of GC signalling (overexpression of $11 \beta$-HSD2 and lack of $11 \beta$-HSD1), the deletion of GR in osteoblasts leads to reduced bone mass. Ablation of GR in osteoblasts decreases bone volume in the trabecular compartments of particular bones when using GR Runx2Cre mice (Rauch et al. 2010). Postnatal tamoxifen-induced ubiquitous deletion of the GR in GRgtROSACreERT2 mice resulted in reduced cancellous bone only in the tibia, and not in the femur or vertebrae (Rapp et al. 2018).

Taken together, dependent on the model, GCs and the GR are slightly anabolic at very distinct bone sites, either femora, vertebrae or tibia. In contrast, MR seems to be rather catabolic and whether it mediates GC effects remains to be elucidated. The different background strains of the respective mouse lines may also contribute to the differential effects on bone mass.

\section{Role of GCs on bone fracture healing}

\section{Clinical problems}

Patients with GIO are at increased risk for fractures, and it can be anticipated that the process of fracture healing is disturbed because of the strong effects of GCs on virtually all participating cell types. However, there are no clinical studies on fracture healing in GIO patients. Furthermore, to date clinical data on bone healing in patients under short-term GC medication are lacking. However, such observations would be extremely important, because GCs are widely prescribed for patients with inflammatory and other disorders. In the following section, we review the literature on the effect of exogenous and endogenous GCs on fracture healing in preclinical models.

\section{Fracture-healing process and participating cell types}

Fracture healing starts with a fine-tuned inflammatory phase with the orchestrated actions of immune cells and cytokines. Because of tissue and vessel disruption, endogenous danger associated molecular patterns (DAMPs), including histones, mitochondrial DNA, and ATP, are released, which trigger activation of the immune system (Schaefer 2014). Immediately, the coagulation cascade is activated, leading to haematoma formation at the fracture site, which is characterised by high lactate, low $\mathrm{pH}$, hypoxia, and immune cells from the blood (Kolar et al. 2011, Hoff et al. 2016). Because of DAMP activity and activation of the coagulation system, the complement cascade is activated, whereby, among other complement molecules, the anaphylatoxins C3a and C5a are produced (Ehrnthaller et al. 2011). C5a in combination with inflammatory mediators released by cells resident in the fracture area and adjacent bone marrow, for example, macrophages, mast cells, mesenchymal cells and endothelial cells, lead to the recruitment of immune cells. The first cells recruited in a high number to the damaged area are polymorphonuclear neutrophils, which secrete chemoattractive cytokines to attract other cells, including monocytes and macrophages, which further clear the fracture zone. In addition to cells of the innate immune system, B- and T-lymphocytes invade the fracture zone

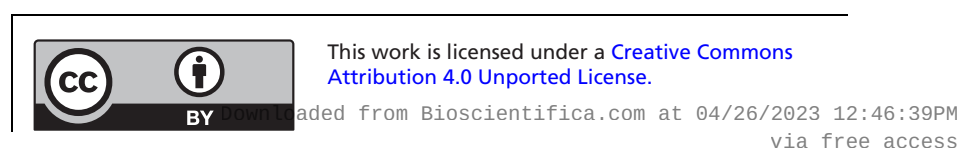


and further modulate the inflammatory milieu. When the inflammatory reaction subsides, the healing cascade progresses to the regenerative phase. Here, periosteal progenitor cells start to proliferate and new bone is deposited via intramembranous ossification remotely from the fracture. Near the fracture, mesenchymal progenitor cells differentiate into the chondrocyte lineage and follow the path of endochondral ossification. Once the fracture gap is bridged by cartilage and thus the mechanical environment is more stable, the callus progressively becomes vascularized and ossification advances from both sides towards the fracture until all cartilage is replaced by woven bone. Subsequently, the callus is resorbed by osteoclasts, remodelled to lamellar bone, and the original bone shape re-established.

Proper resolution of inflammation is mandatory to enable normal fracture healing. Any disturbance of the inflammatory phase is known to influence fracture healing outcome negatively; examples are prolonged inflammation, increased or altered profile of inflammatory mediators as probably caused by concomitant inflammatory disorders, including severe trauma, rheumatoid arthritis, osteoporosis, and diabetes, and experimental depletion of certain immune cells (Mountziaris et al. 2011, Claes et al. 2012, Einhorn \& Gerstenfeld 2015).

GCs could participate in the resolution of inflammation also during fracture healing. However, they have both adverse and beneficial roles on bone cells, depending on the exposure and timing. However, how GCs orchestrate fracture healing remains largely unknown and only recent studies with conditional-knockout mice shed some light into this complicated process, as described below.

\section{GC excess during fracture healing}

Interestingly, only a few studies to date have analysed the effects of GCs on fracture healing. These studies demonstrated different effects of short- and long-term administration of synthetic GCs on bone repair. Shortterm medication with GCs did not significantly disturb bone regeneration (Aslan et al. 2005), whereas longterm administration initiated prior to fracture impaired bone regeneration (Waters et al. 2000). Radiographically, significantly fewer unions were detected together with reduced bone mineralisation, indicating delayed healing (Waters et al. 2000). In agreement with these findings, biomechanical properties of femoral-shaft fractures were significantly reduced after GC administration (Sandberg
\& Aspenberg 2015). The reasons for the delayed bone regeneration under long-term GC treatment are not fully understood. In a mandibular-defect model, impaired osteogenic differentiation, indicated by reduced staining for RUNX2 and osteocalcin, was reported after short-term dexamethasone administration. However, at the endpoint, no differences between control and dexamethasone treatment were noted, indicating a transient effect (Li et al. 2012). Earlier studies reported suppression of collagen synthesis by dexamethasone in calvarial cells (Lukert et al. 1991, Advani et al. 1997), but mechanistic studies on bone regeneration are, to the best of our knowledge, lacking.

\section{Endogenous GCs during fracture healing}

Only a few very recent studies addressed the role of endogenous GCs by studying mice with impaired GC signalling (Weber et al. 2010) or GR deletion (Tu et al. 2014, Rapp et al. 2018). Using Col2.3-11ß-HSD2 mice, disrupting GC signalling in osteoblasts did not affect intramembranous bone healing induced by drill-hole defects in the proximal tibia (Weber et al. 2010). By contrast, GR deletion in chondrocytes in GRCol2CreERT2 mice attenuated endochondral bone healing in tibial metaphyseal fractures by transiently increasing the cartilaginous fraction of the callus, but still resulted in a normal healing response (Tu et al. 2014).

Because the fracture-healing process requires many different cell populations, we recently investigated mice with a tamoxifen-inducible deletion of the GR, GRgtroSACreERT2 mice, in all cells, including bone and immune cells (Rapp et al. 2018). These mice were subjected to a femur osteotomy that was stabilized using an external fixator to allow a reproducible endochondral healing response. The absence of the GR in the immune system in GRgtROSACreERT2 mice caused a greater inflammatory response at the fracture onset, confirmed by elevated interleukin (IL)-6 levels in the serum, increased IL-1 $\beta$ concentrations in the initial fracture haematoma and a significantly higher number of $\mathrm{T}$ cells infiltrating the fracture callus. During callus formation, endochondral ossification was disturbed in the absence of the GR, as confirmed by persisting cartilage in GRCol2CreERT2 mice. In the late healing phase, bony bridging of the fracture gap was reduced, resulting in poor mechanical properties of the healed bones. Therefore, the GR has a protective role in fracture healing by shaping the inflammatory response and by promoting cartilage-to-bone transition ( $\mathrm{Tu}$ et al. 2014, Rapp et al. 2017) (Fig. 2). 


\section{Bone regeneration and GCs}

Because GCs affect fracture healing and regulate proliferation/apoptosis and differentiation of bone precursor and mature bone cells, GCs are also involved in bone regeneration in non-mammalian vertebrates, albeit little is known about their action in this process.

While only some organs regenerate well in adult mammals, non-mammalian vertebrates, in particular salamanders and some teleost fish species, efficiently and completely restore complex organs and structures that do not regenerate in mammals, including appendages (limbs, fins and tails). Bone represents a major tissue in appendages; intriguingly it is completely regenerated after amputation of salamander limbs and fish fins. As discussed previously in this review, progenitor cells are thought to be the cellular source of newly forming osteoblasts during mammalian bone repair, whereas mature osteoblasts (osteocalcin positive) do not appear to contribute to bone repair (Park et al. 2012, Chan et al. 2015, Worthley et al. 2015). Interestingly, non-mammalian vertebrates appear to employ additional cellular mechanisms for bone repair and regeneration. While the source of regenerating osteoblasts in salamander limbs is not yet known, in zebrafish fins differentiated osteocalcin-positive osteoblasts dedifferentiate in response to amputation, revert to a progenitor status and provide a source of regenerating osteoblasts (Knopf et al. 2011).

Very little is known about the molecular mechanisms controlling osteoblast dedifferentiation. The only pathway that has been implicated to date is retinoic acid signalling, which must be downregulated for osteoblast dedifferentiation to occur (Blum \& Begemann 2015, Sehring et al. 2016). To determine additional regulators of this intriguing process, we have employed an unbiased small-molecule screen, which revealed that treatment with exogenous GCs can enhance dedifferentiation ( $\mathrm{R}$ Mira and G Weidinger, unpublished observations). It will be very interesting to characterise the role of endogenous GC signalling in osteoblast dedifferentiation.

While this is ongoing work, the influence of GCs on other aspects of bone biology in non-mammalian species

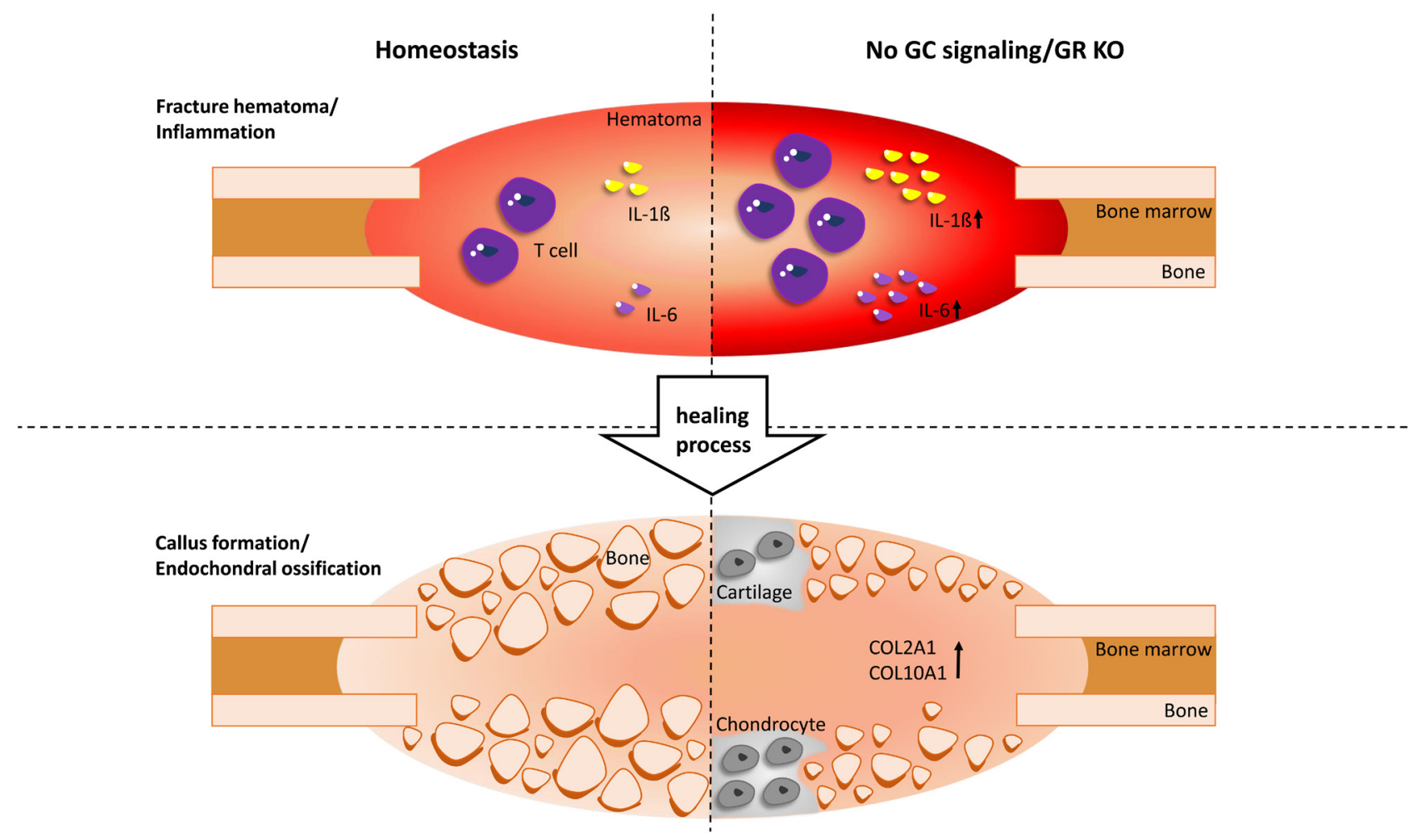

Figure 2

Effect of GCs on fracture healing. During the inflammation phase, in which a fracture haematoma is created, the absence of the glucocorticoid receptor (GR KO) causes an increased inflammatory response. This is shown by elevated interleukin (IL)- 6 and IL-1B levels as well as increased T-cell infiltration. During callus formation, endochondral ossification by chondrocytes is disturbed by persisting cartilage, as confirmed by an elevated expression of collagen type 2 (COL2A 1$)$ and collagen type 10 (COL10A1) and later, bony bridging of the fracture gap is reduced. In summary, the GR has a protective role in fracture healing by influencing the inflammatory response and by promoting cartilage-to-bone transition.

(C) 2018 The authors Published by Bioscientifica Ltd. Printed in Great Britain

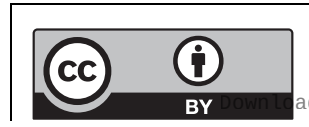

This work is licensed under a Creative Commons Attribution 4.0 Unported License. 
has begun to attract the attention of several researchers. Zebrafish in particular are an attractive model system for in vivo studies of bone formation, repair and regeneration, which are also amenable to large-scale approaches, which could be instrumental for the identification of therapeutically relevant modifiers of bone repair. The negative effects of high-dose GC treatment on bone are conserved in zebrafish, indeed, models of GIO have been established in larvae and in adult scales (Barrett et al. 2006, de Vrieze et al. 2014, Pasqualetti et al. 2015). GCs can also inhibit regenerative growth of zebrafish fins after amputation, as revealed in small-molecule screens for modifiers of regeneration (Mathew et al. 2007, Oppedal \& Goldsmith 2010). As in mammals, systemic GC treatment of zebrafish has complex effects, including suppression of the immune response, reduced osteoblast differentiation, and proliferation, and effects on osteoclast activity (Geurtzen et al. 2017). Tissue-specific manipulations of GR activity have not yet been performed in zebrafish, thus it has to date not been possible to ascertain which of the GC effects on bone, and in particular on osteoblasts, are direct. Interestingly however, in contrast to mammals, prednisolone treatment does not appear to induce osteoblast apoptosis in regenerating zebrafish fins (Geurtzen et al. 2017). The metabolism of endogenous GCs in zebrafish could further differ from mammalians due to the lack of 11ß-HSD1 expression (Baker 2004). Further studies will be needed to test whether other aspects of GC action on bone also differ between mammals and highly regenerative non-mammalian species, and to what extent regeneration-specific events are regulated by endogenous GR signalling.

\section{Conclusion}

GCs and their receptor, the GR, substantially affect the skeleton. Effects of GCs have been intensively studied over recent decades in model organisms, and clinical data about the detrimental effects are abundantly available. Using mouse models with selective ablations of GC signalling and the GR provided some mechanistic knowledge about the requirement of the GR in chondrocytes, osteoblasts and osteoclasts as well as intriguing insights into the cell-autonomous role of the GR concerning proliferation, apoptosis and differentiation of bone cells under steadystate conditions and pharmacological GC exposure. The analysis of the chromatin landscape coupled to GR transcriptional activity - despite being exploited in metabolic tissues and immune cells - has to date not been performed regarding the action in skeletal cells.
Single-cell sequencing in well-designed experiments will help to dissect the still ill-understood mechanisms of different GC exposure on skeletal cells that can be anabolic or catabolic. Furthermore, we have just started to understand how the GR affects the crosstalk between different skeletal compartments (e.g. vasculature and bone-lineage cells, immune system and the skeleton). Advances in in vivo imaging will help to unravel the effects of endogenous and exogenous GCs on the complex processes of bone growth, remodelling and regeneration and fracture healing. This basic research is of utmost importance to understand the pathophysiology of aberrant GC signalling as it occurs during steroid therapies, stress, chronic inflammation and ageing. Only then can we provide proper rationales for therapeutic concepts that allow either time-dependent or tissue-specific delivery of GCs, the development of GR modulators addressing distinct molecular mechanisms to improve therapeutic efficacy and to develop strategies to specifically target GC's adverse effects on bone.

\section{Declaration of interest}

The authors declare that there is no conflict of interest that could be perceived as prejudicing the impartiality of this review.

\section{Funding}

This work was funded by the German Research Foundation within the Collaborative Research Centre 'Danger Response, Disturbance Factors, and Regenerative Potential after Acute Trauma' (CRC 1149, Subproject C02 and $\mathrm{CO3}$ to JT, Al and GW).

\section{References}

Achiou Z, Toumi H, Touvier J, Boudenot A, Uzbekov R, Ominsky MS, Pallu S \& Lespessailles E 2015 Sclerostin antibody and interval treadmill training effects in a rodent model of glucocorticoidinduced osteopenia. Bone 81 691-701. (https://doi.org/10.1016/j. bone.2015.09.010)

Advani S, LaFrancis D, Bogdanovic E, Taxel P, Raisz LG \& Kream BE 1997 Dexamethasone suppresses in vivo levels of bone collagen synthesis in neonatal mice. Bone 20 41-46. (https://doi.org/10.1016/ S8756-3282(96)00314-6)

Almeida M, Han L, Ambrogini E, Weinstein RS \& Manolagas SC 2011 Glucocorticoids and tumor necrosis factor $\alpha$ increase oxidative stress and suppress Wnt protein signaling in osteoblasts. Journal of Biological Chemistry 286 44326-44335. (https://doi.org/10.1074/jbc. M111.283481)

Asada M, Rauch A, Shimizu H, Maruyama H, Miyaki S, Shibamori M, Kawasome H, Ishiyama H, Tuckermann J \& Asahara H 2011 DNA binding-dependent glucocorticoid receptor activity promotes adipogenesis via Kruppel-like factor 15 gene expression. Laboratory Investigation 91 203-215. (https://doi.org/10.1038/ labinvest.2010.170) 
Aslan M, Simsek G \& Yildirim U 2005 Effects of short-term treatment with systemic prednisone on bone healing: an experimental study in rats. Dental Traumatology 21 222-225. (https://doi. org/10.1111/j.1600-9657.2005.00300.x)

Baker ME 2004 Evolutionary analysis of 11beta-hydroxysteroid dehydrogenase-type 1, -type 2, -type 3 and 17beta-hydroxysteroid dehydrogenase-type 2 in fish. FEBS Letters 574 167-170. (https://doi. org/10.1016/j.febslet.2004.08.023)

Barrett R, Chappell C, Quick M \& Fleming A 2006 A rapid, high content, in vivo model of glucocorticoid-induced osteoporosis. Biotechnology Journal 1 651-655. (https://doi.org/10.1002/biot.200600043)

Baschant U \& Tuckermann J 2010 The role of the glucocorticoid receptor in inflammation and immunity. Journal of Steroid Biochemistry and Molecular Biology 120 69-75.

Baschant U, Lane NE \& Tuckermann J 2012 The multiple facets of glucocorticoid action in rheumatoid arthritis. Nature Reviews Rheumatology 8 645-655. (https://doi.org/10.1038/nrrheum.2012.166)

Beato M, Herrlich P \& Schutz G 1995 Steroid hormone receptors: many actors in search of a plot. Cell $\mathbf{8 3}$ 851-857. (https://doi. org/10.1016/0092-8674(95)90201-5)

Beavan S, Horner A, Bord S, Ireland D \& Compston J 2001 Colocalization of glucocorticoid and mineralocorticoid receptors in human bone. Journal of Bone and Mineral Research 16 1496-1504. (https://doi.org/10.1359/jbmr.2001.16.8.1496)

Beier EE, Sheu T-J, Resseguie EA, Takahata M, Awad HA, Cory-Slechta DA \& Puzas JE 2017 Sclerostin activity plays a key role in the negative effect of glucocorticoid signaling on osteoblast function in mice. Bone Research 5 17013. (https://doi.org/10.1038/boneres.2017.13)

Blum N \& Begemann G 2015 Osteoblast de- and redifferentiation are controlled by a dynamic response to retinoic acid during zebrafish fin regeneration. Development 142 2894-2903. (https://doi. org/10.1242/dev.120204)

Canalis E, Mazziotti G, Giustina A \& Bilezikian JP 2007 Glucocorticoidinduced osteoporosis: pathophysiology and therapy. Osteoporosis International 18 1319-1328. (https://doi.org/10.1007/s00198-0070394-0)

Caplan AI 1991 Mesenchymal stem cells. Journal of Orthopaedic Research 9 641-650. (https://doi.org/10.1002/jor.1100090504)

Chan CK, Seo EY, Chen JY, Lo D, McArdle A, Sinha R, Tevlin R, Seita J, Vincent-Tompkins J, Wearda T, et al. 2015 Identification and specification of the mouse skeletal stem cell. Cell 160 285-298. (https://doi.org/10.1016/j.cell.2014.12.002)

Chang J-K, Li C-J, Liao H-J, Wang C-K, Wang G-J \& Ho M-L 2009 Antiinflammatory drugs suppress proliferation and induce apoptosis through altering expressions of cell cycle regulators and proapoptotic factors in cultured human osteoblasts. Toxicology $\mathbf{2 5 8}$ 148-156. (https://doi.org/10.1016/j.tox.2009.01.016)

Chen F, Zhang L, OuYang Y, Guan H, Liu Q \& Ni B 2014 Glucocorticoid induced osteoblast apoptosis by increasing E4BP4 expression via up-regulation of Bim. Calcified Tissue International 94 640-647. (https://doi.org/10.1007/s00223-014-9847-6)

Chirumamilla CS, Palagani A, Kamaraj B, Declerck K, Verbeek MWC, Oksana R, De Bosscher K, Bougarne N, Ruttens B, Gevaert K, et al. 2017 Selective glucocorticoid receptor properties of GSK866 analogs with cysteine reactive warheads. Frontiers in Immunology $\mathbf{8} 1324$. (https://doi.org/10.3389/fimmu.2017.01324)

Claes L, Recknagel S \& Ignatius A 2012 Fracture healing under healthy and inflammatory conditions. Nature Reviews Rheumatology $\mathbf{8}$ 133-143. (https://doi.org/10.1038/nrrheum.2012.1)

Coghlan MJ, Jacobson PB, Lane B, Nakane M, Lin CW, Elmore SW, Kym PR, Luly JR, Carter GW, Turner R, et al. 2003 A novel antiinflammatory maintains glucocorticoid efficacy with reduced side effects. Molecular Endocrinology 17 860-869. (https://doi. org/10.1210/me.2002-0355)

Conaway HH, Henning P, Lie A, Tuckermann J \& Lerner UH 2016 Activation of dimeric glucocorticoid receptors in osteoclast progenitors potentiates RANKL induced mature osteoclast bone resorbing activity. Bone 93 43-54 (https://10.1016/j. bone.2016.08.024)

Conradie MM, Cato AC, Ferris WF, de Wet H, Horsch K \& Hough S 2011 MKP-1 knockout does not prevent glucocorticoid-induced bone disease in mice. Calcified Tissue International 89 221-227. (https:// doi.org/10.1007/s00223-011-9509-x)

Dallas SL, Prideaux M \& Bonewald LF 2013 The osteocyte: an endocrine cell .. and more. Endocrine Reviews 34 658-690. (https://doi. org/10.1210/er.2012-1026)

De Bosscher K \& Haegeman G 2009 Minireview: latest perspectives on antiinflammatory actions of glucocorticoids. Molecular Endocrinology 23 281-291. (https://doi.org/10.1210/me.2008-0283)

De Bosscher K, Beck IM, Dejager L, Bougarne N, Gaigneaux A, Chateauvieux S, Ratman D, Bracke M, Tavernier J, Vanden Berghe W, et al. 2013 Selective modulation of the glucocorticoid receptor can distinguish between transrepression of NF- $\mathrm{kB}$ and AP-1. Cellular and Molecular Life Sciences: CMLS71 143-163. (https://doi.org/10.1007/ s00018-013-1367-4)

De Bosscher K, Beck IM, Ratman D, Berghe WV \& Libert C 2016 Activation of the glucocorticoid receptor in acute inflammation: the SEDIGRAM concept. Trends in Pharmacological Sciences 37 4-16. (https://doi.org/10.1016/j.tips.2015.09.002)

de Vrieze E, van Kessel MA, Peters HM, Spanings FA, Flik G \& Metz JR 2014 Prednisolone induces osteoporosis-like phenotype in regenerating zebrafish scales. Osteoporosis International 25 567-578. (https://doi.org/10.1007/s00198-013-2441-3)

Ehrnthaller C, Ignatius A, Gebhard F \& Huber-Lang M 2011 New insights of an old defense system: structure, function, and clinical relevance of the complement system. Molecular Medicine 17 317-329.

Einhorn TA \& Gerstenfeld LC 2015 Fracture healing: mechanisms and interventions. Nature Reviews Rheumatology 11 45-54. (https://doi. org/10.1038/nrrheum.2014.164)

Espina B, Liang M, Russell RGG \& Hulley PA 2008 Regulation of bim in glucocorticoid-mediated osteoblast apoptosis. Journal of Cellular Physiology 215 488-496. (https://doi.org/10.1002/jcp.21335)

Feng JQ, Ward LM, Liu S, Lu Y, Xie Y, Yuan B, Yu X, Rauch F, Davis SI, Zhang S, et al. 2006 Loss of DMP1 causes rickets and osteomalacia and identifies a role for osteocytes in mineral metabolism. Nature Publishing Group 38 1310-1315. (https://doi. org/10.1038/ng1905)

Frenkel B, White W \& Tuckermann J 2015 Glucocorticoid-induced osteoporosis. Advances in Experimental Medicine and Biology $\mathbf{8 7 2}$ 179-215. (https://doi.org/10.1007/978-1-4939-2895-8_8)

Fumoto T, Ishii K-A, Ito M, Berger S, Schütz G \& Ikeda K 2014 Mineralocorticoid receptor function in bone metabolism and its role in glucocorticoid-induced osteopenia. Biochemical and Biophysical Research Communications 447 407-412. (https://doi.org/10.1016/j. bbrc.2014.03.149)

Geurtzen K, Vernet A, Freidin A, Rauner M, Hofbauer LC, Schneider JE, Brand M \& Knopf F 2017 Immune suppressive and bone inhibitory effects of prednisolone in growing and regenerating Zebrafish tissues. Journal of Bone and Mineral Research 32 2476-2488. (https://doi. org/10.1002/jbmr.3231)

Grcevic D, Pejda S, Matthews BG, Repic D, Wang L, Li H, Kronenberg MS, Jiang X, Maye P, Adams DJ, et al. 2012 In vivo fate mapping identifies mesenchymal progenitor cells. Stem Cells $\mathbf{3 0}$ 187-196. (https://doi.org/10.1002/stem.780)

Harcken C, Riether D, Kuzmich D, Liu P, Betageri R, Ralph M, Emmanuel M, Reeves JT, Berry A, Souza D, et al. 2014 Identification of highly efficacious glucocorticoid receptor agonists with a potential for reduced clinical bone side effects. Journal of Medicinal Chemistry 57 1583-1598. (https://doi.org/10.1021/jm4019178)

Hartmann K, Koenen M, Schauer S, Wittig-Blaich S, Ahmad M, Baschant U \& Tuckermann JP 2016 Molecular actions of glucocorticoids in cartilage and bone during health, disease, and

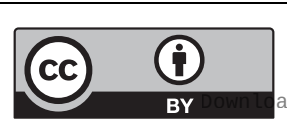

This work is licensed under a Creative Common Attribution 4.0 Unported License. 
steroid therapy. Physiological Reviews 96 409-447. (https://doi. org/10.1152/physrev.00011.2015)

Heinrichs C, Yanovski JA, Roth AH, Yu YM, Domene HM, Yano K, Cutler GB Jr \& Baron J 1994 Dexamethasone increases growth hormone receptor messenger ribonucleic acid levels in liver and growth plate. Endocrinology 135 1113-1118. (https://doi.org/10.1210/ endo.135.3.8070354)

Henriksen K, Karsdal MA \& Martin TJ 2014 Osteoclast-derived coupling factors in bone remodeling. Calcified Tissue International 94 88-97. (https://doi.org/10.1007/s00223-013-9741-7)

Hofbauer LC, Gori F, Riggs BL, Lacey DL, Dunstan CR, Spelsberg TC \& Khosla S 1999 Stimulation of osteoprotegerin ligand and inhibition of osteoprotegerin production by glucocorticoids in human osteoblastic lineage cells: potential paracrine mechanisms of glucocorticoid-induced osteoporosis. Endocrinology 140 4382-4389. (https://doi.org/10.1210/endo.140.10.7034)

Hofbauer LC, Zeitz U, Schoppet M, Skalicky M, Schuler C, Stolina M, Kostenuik PJ \& Erben RG 2009 Prevention of glucocorticoid-induced bone loss in mice by inhibition of RANKL. Arthritis and Rheumatology 60 1427-1437. (https://doi.org/10.1002/art.24445)

Hoff P, Gaber T, Strehl C, Schmidt-Bleek K, Lang A, Huscher D, Burmester GR, Schmidmaier G, Perka C, Duda GN, et al. 2016 Immunological characterization of the early human fracture hematoma. Immunologic Research 64 1195-1206. (https://doi. org/10.1007/s12026-016-8868-9)

Hong JM, Teitelbaum SL, Kim TH, Ross FP, Kim SY \& Kim HJ 2011 Calpain-6, a target molecule of glucocorticoids, regulates osteoclastic bone resorption via cytoskeletal organization and microtubule acetylation. Journal of Bone and Mineral Research 26 657-665. (https:// doi.org/10.1002/jbmr.241)

Horsch K, de Wet H, Schuurmans MM, Allie-Reid F, Cato ACB, Cunningham J, Burrin JM, Hough FS \& Hulley PA 2007 Mitogenactivated protein kinase phosphatase 1 /dual specificity phosphatase 1 mediates glucocorticoid inhibition of osteoblast proliferation. Molecular Endocrinology 21 2929-2940. (https://doi.org/10.1210/ me.2007-0153)

Hu X, Du S, Tunca C, Braden T, Long KR, Lee J, Webb EG, Dietz JD, Hummert S, Rouw S, et al. 2011 The antagonists but not partial agonists of glucocorticoid receptor ligands show substantial side effect dissociation. Endocrinology 152 3123-3134. (https://doi. org/10.1210/en.2010-1447)

Hübner S, Dejager L, Libert C \& Tuckermann JP 2015 The glucocorticoid receptor in inflammatory processes: transrepression is not enough. Biological Chemistry 396 1223-1231. (https://doi.org/10.1515/hsz2015-0106)

Humphrey EL, Williams JHH, Davie MWJ \& Marshall MJ 2006 Effects of dissociated glucocorticoids on OPG and RANKL in osteoblastic cells. Bone 38 652-661. (https://doi.org/10.1016/j.bone.2005.10.004)

Jia D, O’Brien CA, Stewart SA, Manolagas SC \& Weinstein RS 2006 Glucocorticoids act directly on osteoclasts to increase their life span and reduce bone density. Endocrinology 147 5592-5599. (https://doi. org/10.1210/en.2006-0459)

Jia J, Yao W, Guan M, Dai W, Shahnazari M, Kar R, Bonewald L, Jiang JX \& Lane NE 2011 Glucocorticoid dose determines osteocyte cell fate. FASEB Journal 25 3366-3376. (https://doi.org/10.1096/fj.11-182519)

Jilka RL, Weinstein RS, Bellido T, Roberson P, Parfitt AM \& Manolagas SC 1999 Increased bone formation by prevention of osteoblast apoptosis with parathyroid hormone. Journal of Clinical Investigation $\mathbf{1 0 4}$ 439-446. (https://doi.org/10.1172/JCI6610)

Jilka RL, Noble B \& Weinstein RS 2013 Osteocyte apoptosis. Bone $\mathbf{5 4}$ 264-271. (https://doi.org/10.1016/j.bone.2012.11.038)

Joëls M \& de Kloet ER 201730 years of the mineralocorticoid receptor: the brain mineralocorticoid receptor: a saga in three episodes. Journal of Endocrinology 234 T49-T66. (https://doi.org/10.1530/JOE-16-0660)

Jux C, Leiber K, Hugel U, Blum W, Ohlsson C, Klaus G \& Mehls O 1998 Dexamethasone impairs growth hormone (GH)-stimulated growth by suppression of local insulin-like growth factor (IGF)-I production and expression of GH- and IGF-I-receptor in cultured rat chondrocytes. Endocrinology 139 3296-3305. (https://doi. org/10.1210/endo.139.7.6099)

Kalak R, Zhou H, Street J, Day RE, Modzelewski JR, Spies CM, Liu PY, Li G, Dunstan CR \& Seibel MJ 2009 Endogenous glucocorticoid signalling in osteoblasts is necessary to maintain normal bone structure in mice. Bone $\mathbf{4 5}$ 61-67. (https://doi.org/10.1016/j. bone.2009.03.673)

Kassem M \& Bianco P 2015 Skeletal stem cells in space and time. Cell 160 17-19. (https://doi.org/10.1016/j.cell.2014.12.034)

Kawai M, de Paula FJA \& Rosen CJ 2012 New insights into osteoporosis: the bone-fat connection. Journal of Internal Medicine 272 317-329. (https://doi.org/10.1111/j.1365-2796.2012.02564.x)

Kim H-J, Zhao H, Kitaura H, Bhattacharyya S, Brewer JA, Muglia LJ, Ross FP \& Teitelbaum SL 2006 Glucocorticoids suppress bone formation via the osteoclast. Journal of Clinical Investigation $\mathbf{1 1 6}$ 2152-2160. (https://doi.org/10.1172/JCI28084)

Knopf F, Hammond C, Chekuru A, Kurth T, Hans S, Weber CW, Mahatma G, Fisher S, Brand M, Schulte-Merker S, et al. 2011 Bone regenerates via dedifferentiation of osteoblasts in the zebrafish fin. Developmental Cell 20 713-724. (https://doi.org/10.1016/j. devcel.2011.04.014)

Kolar P, Gaber T, Perka C, Duda GN \& Buttgereit F 2011 Human early fracture hematoma is characterized by inflammation and hypoxia. Clinical Orthopaedics and Related Research 469 3118-3126. (https:// doi.org/10.1007/s11999-011-1865-3)

Komori T 2016 Glucocorticoid signaling and bone biology. Hormone and Metabolic Research 48 755-763. (https://doi. org/10.1055/s-0042-110571)

Kusumbe AP, Ramasamy SK \& Adams RH 2014 Coupling of angiogenesis and osteogenesis by a specific vessel subtype in bone. Nature $\mathbf{5 0 7}$ 323-328. (https://doi.org/10.1038/nature13145)

Lan NC, Graham B, Bartter FC \& Baxter JD 1982 Binding of steroids to mineralocorticoid receptors: implications for in vivo occupancy by glucocorticoids. Journal of Clinical Endocrinology and Metabolism $\mathbf{5 4}$ 332-342.(https://doi.org/10.1210/jcem-54-2-332)

Li J, Wang X, Zhou C, Liu L, Wu Y, Wang D \& Jiang H 2012 Perioperative glucocorticosteroid treatment delays early healing of a mandible wound by inhibiting osteogenic differentiation. Injury $\mathbf{4 3}$ 1284-1289. (https://doi.org/10.1016/j.injury.2012.04.014)

Lim HW, Uhlenhaut NH, Rauch A, Weiner J, Hubner S, Hubner N, Won KJ, Lazar MA, Tuckermann J \& Steger DJ 2015 Genomic redistribution of GR monomers and dimers mediates transcriptional response to exogenous glucocorticoid in vivo. Genome Research $\mathbf{2 5}$ 836-844. (https://doi.org/10.1101/gr.188581.114)

Liu P, Baumgart M, Groth M, Wittmann J, Jack HM, Platzer M, Tuckermann JP \& Baschant U 2016 Dicer ablation in osteoblasts by Runx2 driven cre-loxP recombination affects bone integrity, but not glucocorticoid-induced suppression of bone formation. Scientific Reports 6 32112. (https://doi.org/10.1038/srep32112)

Liu P, Lee S, Knoll J, Rauch A, Ostermay S, Luther J, Malkusch N, Lerner UH, Zaiss MM, Neven M, et al. 2017 Loss of menin in osteoblast lineage affects osteocyte-osteoclast crosstalk causing osteoporosis. Cell Death and Differentiation 24 672-682. (https://doi. org/10.1038/cdd.2016.165)

Lukert B, Mador A, Raisz LG \& Kream BE 1991 The role of DNA synthesis in the responses of fetal rat calvariae to cortisol. Journal of Bone and Mineral Research 6 453-460. (https://doi.org/10.1002/ jbmr.5650060505)

Mak W, Shao X, Dunstan CR, Seibel MJ \& Zhou H 2009 Biphasic glucocorticoid-dependent regulation of Wnt expression and its inhibitors in mature osteoblastic cells. Calcified Tissue International 85 538-545. (https://doi.org/10.1007/s00223-009-9303-1)

Mathew LK, Sengupta S, Kawakami A, Andreasen EA, Lohr CV, Loynes CA, Renshaw SA, Peterson RT \& Tanguay RL 2007 Unraveling

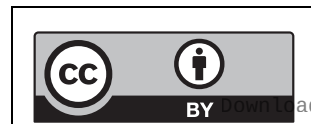

This work is licensed under a Creative Commons Attribution 4.0 Unported License. 
tissue regeneration pathways using chemical genetics. Journal of Biological Chemistry 282 35202-35210. (https://doi.org/10.1074/jbc. M706640200)

Matic I, Matthews BG, Wang X, Dyment NA, Worthley DL, Rowe DW, Grcevic D \& Kalajzic I 2016 Quiescent bone lining cells are a major source of osteoblasts during adulthood. Stem Cells 34 2930-2942. (https://doi.org/10.1002/stem.2474)

Mifsud KR \& Reul JMHM 2016 Acute stress enhances heterodimerization and binding of corticosteroid receptors at glucocorticoid target genes in the hippocampus. PNAS 113 11336-11341. (https://doi. org/10.1073/pnas.1605246113)

Miner JN, Ardecky B, Benbatoul K, Griffiths K, Larson CJ, Mais DE, Marschke K, Rosen J, Vajda E, Zhi L, et al. 2007 Antiinflammatory glucocorticoid receptor ligand with reduced side effects exhibits an altered protein-protein interaction profile. PNAS 104 19244-19249. (https://doi.org/10.1073/pnas.0705517104)

Mountziaris PM, Spicer PP, Kasper FK \& Mikos AG 2011 Harnessing and modulating inflammation in strategies for bone regeneration. Tissue Engineering: Part B, Reviews 17 393-402. (https://doi.org/10.1089/ten. teb.2011.0182)

Nakashima T, Hayashi M, Fukunaga T, Kurata K, Oh-Hora M, Feng JQ, Bonewald LF, Kodama T, Wutz A, Wagner EF, et al. 2011 Evidence for osteocyte regulation of bone homeostasis through RANKL expression. Nature Medicine 17 1231-1234. (https://doi.org/10.1038/ $\mathrm{nm} .2452)$

O'Brien CA, Jia D, Plotkin LI, Bellido T, Powers CC, Stewart SA, Manolagas SC \& Weinstein RS 2004 Glucocorticoids act directly on osteoblasts and osteocytes to induce their apoptosis and reduce bone formation and strength. Endocrinology 145 1835-1841.

Ono N, Ono W, Nagasawa T \& Kronenberg HM 2014 A subset of chondrogenic cells provides early mesenchymal progenitors in growing bones. Nature Cell Biology 16 1157-1167. (https://doi. org/10.1038/ncb3067)

Oppedal D \& Goldsmith MI 2010 A chemical screen to identify novel inhibitors of fin regeneration in zebrafish. Zebrafish 7 53-60. (https://doi.org/10.1089/zeb.2009.0633)

Park D, Spencer JA, Koh BI, Kobayashi T, Fujisaki J, Clemens TL, Lin CP, Kronenberg HM \& Scadden DT 2012 Endogenous bone marrow MSCs are dynamic, fate-restricted participants in bone maintenance and regeneration. Cell Stem Cell 10 259-272. (https://doi. org/10.1016/j.stem.2012.02.003)

Pasqualetti S, Congiu T, Banfi G \& Mariotti M 2015 Alendronate rescued osteoporotic phenotype in a model of glucocorticoid-induced osteoporosis in adult zebrafish scale. International Journal of Experimental Pathology 96 11-20. (https://doi.org/10.1111/iep.12106)

Piemontese M, Onal M, Xiong J, Wang Y, Almeida M, Thostenson JD, Weinstein RS, Manolagas SC \& O’Brien CA 2015 Suppression of autophagy in osteocytes does not modify the adverse effects of glucocorticoids on cortical bone. Bone 75 18-26. (https://doi. org/10.1016/j.bone.2015.02.005)

Piemontese M, Xiong J, Fujiwara Y, Thostenson JD \& O’Brien CA 2016 Cortical bone loss caused by glucocorticoid excess requires RANKL production by osteocytes and is associated with reduced OPG expression in mice. American Journal of Physiology-Endocrinology and Metabolism 311 E587-E593. (https://doi.org/10.1152/ ajpendo.00219.2016)

Plotkin LI, Weinstein RS, Parfitt AM, Roberson PK, Manolagas SC \& Bellido T 1999 Prevention of osteocyte and osteoblast apoptosis by bisphosphonates and calcitonin. Journal of Clinical Investigation 104 1363-1374. (https://doi.org/10.1172/JCI6800)

Plotkin LI, Manolagas SC \& Bellido T 2007 Glucocorticoids induce osteocyte apoptosis by blocking focal adhesion kinase-mediated survival. Evidence for inside-out signaling leading to anoikis. Journal of Biological Chemistry 282 24120-24130. (https://doi.org/10.1074/ jbc.M611435200)
Presman DM, Ogara MF, Stortz M, Alvarez LD, Pooley JR, Schiltz RL, Grøntved L, Johnson TA, Mittelstadt PR, Ashwell JD, et al. 2014 Live cell imaging unveils multiple domain requirements for in vivo dimerization of the glucocorticoid receptor. PLoS Biology 12 e1001813. (https://doi.org/10.1371/journal.pbio.1001813)

Rapp AE, Hachemi Y, Kemmler J, Koenen M, Tuckermann J \& Ignatius A 2018 Induced global deletion of glucocorticoid receptor impairs fracture healing. FASEB Journal 32 2235-2245. (https://doi. org/10.1096/fj.201700459RR)

Rauch A, Seitz S, Baschant U, Schilling AF, Illing A, Stride B, Kirilov M, Mandic V, Takacz A, Schmidt-Ullrich R, et al. 2010 Glucocorticoids suppress bone formation by attenuating osteoblast differentiation via the monomeric glucocorticoid receptor. Cell Metabolism 11 517-531. (https://doi.org/10.1016/j.cmet.2010.05.005)

Rauch A, Gossye V, Bracke D, Gevaert E, Jacques P, Van Beneden K, Vandooren B, Rauner M, Hofbauer LC, Haegeman G, et al. 2011 An anti-inflammatory selective glucocorticoid receptor modulator preserves osteoblast differentiation. FASEB Journal 25 1323-1332. (https://doi.org/10.1096/fj.10-173393)

Rauner M, Goettsch C, Stein N, Thiele S, Bornhaeuser M, De Bosscher K, Haegeman G, Tuckermann J \& Hofbauer LC 2011 Dissociation of osteogenic and immunological effects by the selective glucocorticoid receptor agonist, compound $\mathrm{A}$, in human bone marrow stromal cells. Endocrinology 152 103-112. (https://doi.org/10.1210/en.2010-0456)

Reichardt HM, Tuckermann JP, Göttlicher M, Vujic M, Weih F, Angel P, Herrlich P \& Schutz G 2001 Repression of inflammatory responses in the absence of DNA binding by the glucocorticoid receptor. EMBO Journal 20 7168-7173. (https://doi.org/10.1093/emboj/20.24.7168)

Rosen CJ \& Bouxsein ML 2006 Mechanisms of disease: is osteoporosis the obesity of bone? Nature Clinical Practice: Rheumatology 2 35-43. (https://doi.org/10.1038/ncprheum0070)

Salem HK \& Thiemermann C 2010 Mesenchymal stromal cells: current understanding and clinical status. Stem Cells 28 585-596. (https:// doi.org/10.1002/stem.269)

Sandberg OH \& Aspenberg P 2015 Glucocorticoids inhibit shaft fracture healing but not metaphyseal bone regeneration under stable mechanical conditions. Bone and Joint Research 4 170-175. (https:// doi.org/10.1302/2046-3758.410.2000414)

Sato AY, Cregor M, Delgado-Calle J, Condon KW, Allen MR, Peacock M, Plotkin LI \& Bellido T 2016 Protection from glucocorticoid-induced osteoporosis by anti-catabolic signaling in the absence of Sost/ sclerostin. Journal of Bone and Mineral Research 31 1791-1802. (https://doi.org/10.1002/jbmr.2869)

Schäcke H, Berger M, Rehwinkel H \& Asadullah K 2007 Selective glucocorticoid receptor agonists (SEGRAs): novel ligands with an improved therapeutic index. Molecular and Cellular Endocrinology 275 109-117. (https://doi.org/10.1016/j.mce.2007.05.014)

Schaefer L 2014 Complexity of danger: the diverse nature of damageassociated molecular patterns. Journal of Biological Chemistry 289 35237-35245. (https://doi.org/10.1074/jbc.R114.619304)

Schiller BJ, Chodankar R, Watson LC, Stallcup MR \& Yamamoto KR 2014 Glucocorticoid receptor binds half sites as a monomer and regulates specific target genes. Genome Biology 15 3181. (https://doi. org/10.1186/s13059-014-0418-y)

Sehring IM, Jahn C \& Weidinger G 2016 Zebrafish fin and heart: what's special about regeneration? Current Opinion in Genetics and Development 40 48-56. (https://doi.org/10.1016/j.gde.2016.05.011)

Sher LB, Woitge HW, Adams DJ, Gronowicz GA, Krozowski Z, Harrison JR \& Kream BE 2004 Transgenic expression of 11betahydroxysteroid dehydrogenase type 2 in osteoblasts reveals an anabolic role for endogenous glucocorticoids in bone. Endocrinology 145 922-929. (https://doi.org/10.1210/en.2003-0655)

Sher LB, Harrison JR, Adams DJ \& Kream BE 2006 Impaired cortical bone acquisition and osteoblast differentiation in mice with osteoblast-targeted disruption of glucocorticoid signaling. Calcified

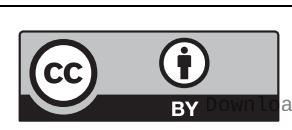

This work is licensed under a Creative Common Attribution 4.0 Unported License. 
Tissue International 79 118-125. (https://doi.org/10.1007/s00223-0050297-z)

Shi J, Wang L, Zhang H, Jie Q, Li X, Shi Q, Huang Q, Gao B, Han Y, Guo K, et al. 2015 Glucocorticoids: dose-related effects on osteoclast formation and function via reactive oxygen species and autophagy. Bone 79 222-232. (https://doi.org/10.1016/j.bone.2015.06.014)

Smink JJ, Koedam JA, Koster JG \& van Buul-Offers SC 2002 Dexamethasone-induced growth inhibition of porcine growth plate chondrocytes is accompanied by changes in levels of IGF axis components. Journal of Endocrinology 174 343-352. (https://doi. org/10.1677/joe.0.1740343)

Stahn C \& Buttgereit F 2008 Genomic and nongenomic effects of glucocorticoids. Nature Clinical Practice: Rheumatology 4 525-533. (https://doi.org/10.1038/ncprheum0898)

Strehl C, van der Goes MC, Bijlsma JW, Jacobs JW \& Buttgereit F 2017 Glucocorticoid-targeted therapies for the treatment of rheumatoid arthritis. Expert Opinion on Investigational Drugs 26 187-195. (https:// doi.org/10.1080/13543784.2017.1276562)

Sui B, Hu C, Liao L, Chen Y, Zhang X, Fu X, Zheng C, Li M, Wu L, Zhao X, et al. 2016 Mesenchymal progenitors in osteopenias of diverse pathologies: differential characteristics in the common shift from osteoblastogenesis to adipogenesis. Scientific Reports 630186. (https://doi.org/10.1038/srep30186)

Sundahl N, Bridelance J, Libert C, De Bosscher K \& Beck IM 2015 Selective glucocorticoid receptor modulation: new directions with non-steroidal scaffolds. Pharmacology and Therapeutics 152 28-41. (https://doi.org/10.1016/j.pharmthera.2015.05.001)

Surjit M, Ganti KP, Mukherji A, Ye T, Hua G, Metzger D, Li M \& Chambon P 2011 Widespread negative response elements mediate direct repression by agonist-liganded glucocorticoid receptor. Cell 145 224-241. (https://doi.org/10.1016/j.cell.2011.03.027)

Thiele S, Ziegler N, Tsourdi E, De Bosscher K, Tuckermann JP, Hofbauer LC \& Rauner M 2012 Selective glucocorticoid receptor modulation maintains bone mineral density in mice. Journal of Bone and Mineral Research 27 2242-2250. (https://doi.org/10.1002/ jbmr.1688)

Tu J, Henneicke H, Zhang Y, Stoner S, Cheng TL, Schindeler A, Chen D, Tuckermann J, Cooper MS, Seibel MJ, et al. 2014 Disruption of glucocorticoid signaling in chondrocytes delays metaphyseal fracture healing but does not affect normal cartilage and bone development. Bone 69 12-22. (https://doi.org/10.1016/j.bone.2014.08.016)

Van Staa TP, Leufkens HG, Abenhaim L, Zhang B \& Cooper C 2000 Use of oral corticosteroids and risk of fractures. Journal of Bone and Mineral Research 15 993-1000. (https://doi.org/10.1359/ jbmr.2000.15.6.993)

van Weert LTCM \& Meijer OC 2017 Genomic Aspects of Corticosteroid Action in the Brain, pp 149-157. Elsevier:Amsterdam, Netherlands.

Waters RV, Gamradt SC, Asnis P, Vickery BH, Avnur Z, Hill E \& Bostrom M 2000 Systemic corticosteroids inhibit bone healing in a rabbit ulnar osteotomy model. Acta Orthopaedica Scandinavica 71 316-321. (https://doi.org/10.1080/000164700317411951)
Weber AJ, Li G, Kalak R, Street J, Buttgereit F, Dunstan CR, Seibel MJ \& Zhou H 2010 Osteoblast-targeted disruption of glucocorticoid signalling does not delay intramembranous bone healing. Steroids $\mathbf{7 5}$ 282-286. (https://doi.org/10.1016/j.steroids.2010.01.005)

Weikum ER, Knuesel MT, Ortlund EA \& Yamamoto KR 2017 Glucocorticoid receptor control of transcription: precision and plasticity via allostery. Nature Reviews Molecular Cell Biology 18 159-174. (https://doi.org/10.1038/nrm.2016.152)

Weinstein RS 2012 Glucocorticoid-induced osteonecrosis. Endocrine 41 183-190. (https://doi.org/10.1007/s12020-011-9580-0)

Weinstein RS, Jilka RL, Parfitt AM \& Manolagas SC 1998 Inhibition of osteoblastogenesis and promotion of apoptosis of osteoblasts and osteocytes by glucocorticoids. Potential mechanisms of their deleterious effects on bone. Journal of Clinical Investigation 102 274-282. (https://doi.org/10.1172/JCI2799)

Weinstein RS, Wan C, Liu Q, Wang Y, Almeida M, O'Brien CA, Thostenson J, Roberson PK, Boskey AL, Clemens TL, et al. 2010 Endogenous glucocorticoids decrease skeletal angiogenesis, vascularity, hydration, and strength in 21-month-old mice. Aging Cell 9 147-161. (https://doi.org/10.1111/j.1474-9726.2009.00545.x)

Weinstein RS, Hogan EA, Borrelli MJ, Liachenko S, O'Brien CA \& Manolagas SC 2017 The pathophysiological sequence of glucocorticoid-induced osteonecrosis of the femoral head in male mice. Endocrinology 158 3817-3831. (https://doi.org/10.1210/ en.2017-00662)

Wood CL, Soucek O, Wong SC, Zaman F, Farquharson C, Sävendahl L \& Ahmed SF 2017 Animal models to explore the effects of glucocorticoids on skeletal growth and structure. Journal of Endocrinology 236 R69-R91. (https://doi.org/10.1530/JOE-17-0361)

Worthley DL, Churchill M, Compton JT, Tailor Y, Rao M, Si Y, Levin D, Schwartz MG, Uygur A, Hayakawa Y, et al. 2015 Gremlin 1 identifies a skeletal stem cell with bone, cartilage, and reticular stromal potential. Cell 160 269-284. (https://doi.org/10.1016/j. cell.2014.11.042)

Xiong J, Onal M, Jilka RL, Weinstein RS, Manolagas SC \& O'Brien CA 2011 Matrix-embedded cells control osteoclast formation. Nature Medicine 17 1235-1241. (https://doi.org/10.1038/nm.2448)

Yao W, Dai W, Jiang L, Lay EY, Zhong Z, Ritchie RO, Li X, Ke H \& Lane NE 2016 Sclerostin-antibody treatment of glucocorticoidinduced osteoporosis maintained bone mass and strength. Osteoporosis International 27 283-294. (https://doi.org/10.1007/ s00198-015-3308-6)

Zaman F, Chrysis D, Huntjens K, Chagin A, Takigawa M, Fadeel B \& Savendahl L 2014 Dexamethasone differentially regulates Bcl-2 family proteins in human proliferative chondrocytes: role of proapoptotic Bid. Toxicology Letters 224 196-200. (https://doi. org/10.1016/j.toxlet.2013.10.020)

Zhou H, Mak W, Kalak R, Street J, Fong-Yee C, Zheng Y, Dunstan CR \& Seibel MJ 2009 Glucocorticoid-dependent Wnt signaling by mature osteoblasts is a key regulator of cranial skeletal development in mice. Development 136 427-436. (https://doi.org/10.1242/dev.027706)

Received in final form 1 March 2018

Accepted 27 March 2018

Accepted Preprint published online 27 March 2018 http://jme.endocrinology-journals.org https://doi.org/10.1530/JME-18-0024
(C) 2018 The authors Published by Bioscientifica Ltd. Printed in Great Britain

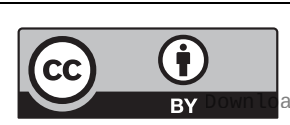

This work is licensed under a Creative Common Attribution 4.0 Unported License.

ded from Bioscientifica.com at 04/26/2023 12:46:39PM 